\title{
Çocuk edebiyatı klasiklerinde çeviri yaklaşımları: Uyarlama, yeniden yazma, kültürel müdahale
}

\section{Necdet NEYDİM1}

\begin{abstract}
APA: Neydim, N. (2020). Çocuk edebiyatı klasiklerinde çeviri yaklaşımları: Uyarlama, yeniden yazma, kültürel müdahale. RumeliDE Dil ve Edebiyat Araştırmaları Dergisi, (19), 851-858. DOI: $10.29000 /$ rumelide. 752864 .
\end{abstract}

$\ddot{O} \mathbf{z}$

Klasikler yaklaşı 16o yıldır edebiyat dizgemizde saygın bir biçimde yer almaktadır. Genel anlamda baktığımızda bu saygınlığın süreç içinde başlangıç anlamını yitirip kutsallaştırılan bir edebiyat alanına dönüştüğünü saptamak mümkündür. Modernleşme sürecinde işlevsel bir amaçla kullanılan bu metinler gelişen süreç içinde farklı anlamlar yüklenerek yeni işlevler kazanmış ve çevirmen, yayıncı ve okur üçgeninde yeni anlamlar yüklenerek edebiyat dizgesinde hep kendini ön planda tutmayı gerçekleştirebilmiştir. $\mathrm{Bu}$ sürecin çocuk edebiyatındaki yeri de benzer bir şekilde oluşmuştur. Çalışmamızdaki amacımız bunu görünür kılmaktır.

Anahtar kelimeler: Çeviri çocuk edebiyatı, çeviri politikaları, çeviri yaklaşımları, uyarlama, klasikler

\section{Translation approaches to children's classics: Adaptation, rewriting, cultural interference}

\begin{abstract}
Classics have been a major part of canonized books for children in Turkish literary system for about 160 years. In general terms, it might be possible to pinpoint rightfully that dignity arising from the canonized status of classic books has lost its initial meaning and that children's classics in Turkish have been turned into a kind of literature, which is consecrated. Classic books, which were used for a given functional purpose during the process of modernization in Turkey, have gained a different momentum by attaining new functions and meanings throughout the ongoing process in question. Therefore, these canonized books remain persistently at the forefront of the literary system in the triangle of translator, publisher and reader. The canonization process and transformations have developed in a similar vein in children's literature. The aim in our study is to shed light on the canonization process of children's classics in the field of children's literature.
\end{abstract}

Keywords: Translated children's literature, politics of translation, translation approaches, adaptation, classics

\section{Çocuk edebiyatının ortaya çıkışı}

Çocuk ve gençlik edebiyatı moderleşme, sanayileşme ve kentleşme sonucunda üretim yapısının ve sosyal ilişkilerin değişmesine neden olmuş ve bu neden yeni bir toplum yapısına gereksinme duyarken çocuğa dönük yaklaşımını da değiştirmiştir. Bu süreç çocuğa dönük olarak onun artık feodal

1 Doç. Dr., İstanbul Üniversitesi, Edebiyat Fakültesi Çeviribilim Bölümü, Almanca Mütercim Tercümanlı ABD (İstanbul, Türkiye), neydim@istanbul.edu.tr, oooo-0002-5708-6496 [Makale kaylt tarihi: 09.03.2020-kabul tarihi: 16.04.2020; DOI: $10.29000 /$ rumelide.752864] 
ilişkilerde olduğu gibi yedi yaşından itibaren yetişkinler dünyasına katılmasıını engellemiş ve ona yeni bir dünyanın kapılarını açmıştır. Bu dünya okuldur. Okula gidecek olan çocuğa dönük bir edebiyatın gereksinmesi de doğası gereğidir ve bu nedenle çocuğa dönük bir edebiyat yaratılmaya çalışılmış ve çocuk edebiyatı bir zorunluluk olarak ortaya çıkmıştır.

\section{Edebiyatın oluşum süreci}

ÇGE nın okur kitlesi hazır bir kitle değildi. Aksine bu okur kitlesi o güne dek çocuk olma özelliklerini ve hakkını yedi yaşında kaybettiği için okur olma sürecini ancak eğitim yoluyla kazanmıştır. ÇGE okurun talebiyle ortaya çlkmamış aksine yetişkinler dünyasının ona dönük bir edebiyat yaratma kaygısı bunu oluşturmuştur. Bu alanı oluştururken temel amaç çocuğu eğitmek ve dönemsel bağlamda baktığımızda sistemin gereksindiği insan tipini oluşturmakta bu alandan yararlanmaktır.

\section{Yüzyıl anlayışı}

19. yüzyıla hakim olan temel anlayış akla ve aydınlanmaya dayalı bir anlayış olarak kendine yer bulmuş bir anlayış olarak ÇGE'nın oluşumunu sağlarken, yanısıra buna dönük tepkileri içeren metinler de alanda yer almaya başlamıştır.

Collodi, Pinokyo'da (1883) modernitenin gereksindiği insan tipini oluşturmak için eğitime yönlendirilmiş çocuğun, bu süreçte yaşadığı uyumsuzlukları ve bunların aşılmasını anlatırken aynı zamanda bu temel anlayışa göre ehlileştirmeden söz eder ve romanın sonunda bunu başarır.

Pinokyo, fantastik bir kurguda modernleşme ve aydınlanma çerçevesinde eğitilme sürecinin tanıklığını yaparken dönemsel bağlamda başka bir metin bu sürece karşı bir paradigma oluşturur: Spyri, Heidi romanında kentleşmeye, katı bir eğitim sistemine karşı çıkarken bunu doğaya dönüş ve tanrıya sı̆̆ınma motifiyle gerçekleştirmeye çalışır.

\section{Kız ve erkek çocuk edebiyatı}

19. yüzyılın ikinci yarısındaki yayınlara baktığımızda ÇGE daha didaktik ve tek tipçi bir anlayışı temsil edenler metinler daha bir görünür olmaya başlar. Bu dönemde başlayan ve bir sonraki yüzyılda sürmeye devam eden bu anlayış idealize erkek ve kız çocuk figürleri çizmeye başlar ve bu ikinci dünya savaşının sonuna kadar sürer. Altmışlı yıllardan sonra gelişen yeni anlayışlar başlangıçta katı bir sol çocuk edebiyatı olarak ortaya çıssa da bunun kabul görmemesi nedeniyle daha olumlu bir sürece evrilir ve bugün tanıklığını yaptığımız eşitlikçi ve çocuk gerçeğine dayalı bir edebiyat anlayışına dönüşür. (Krş.Neydim,2020,30)

\section{Türkiye'deki gelişmeler}

Osmanlı'da ve ardından Türkiye'deki gelişimlere genel olarak göz atacak olursak Osmanlı'da Fenelon'un Telemak eserinın 1859 da Yusuf Kamil Paşa'nın çevirisiyle ÇGE alanında ilk çeviri kitap olarak yayınlanır.(karş Alpaslan, 2007,16) Bu sürecin öncü dönüm noktası olan 1839 Tanzimat Fermanı salt bir politik reform olmamış aynı zamanda sosyal değişimlerin de başlangıcı olmuştur. Bu, eğitimin yanısıra aydınların öncülüğünde başlamış, çocuk edebiyatı alanının gelişmesine de yol açan bir süreç ortaya çıkmıştır.. O dönem aydınları hem eğitim anlayışını hem de buna bağlı olarak çocuk edebiyatının oluşumunu ele alan girişimlerde bulunmuşlardır. Çocuk dergilerine yaptıkları çeviriler ve uyarlamalar buna dönük örnekler olarak ele alınabilir. 


\section{Çocuk Dergileri}

Mümeyyiz Dergisi ilk çocuk dergisidir ve 1869 da yayınlanır. Derginin en göze çarpan özelliği çocukları okumaya teşvik etmesi ve kız çocukların da okumasının önemini vurgulamasıdır.'Çocuklara Arkadaş'1882; 'Vasıta-i Terakki'1882; "Çocuklara Mahsus Gazete"1896; “Çocuklara Rehber"1897, "Çocuk Bahçesi” 1897'; "Arkadaş" İsmet Kür’ün araştırmasında ele aldığı dergilere örnektir ve Kür 1869 dan başlayıp Harf Devrimine kadar yaşanan süreçte yayımlanan dergilerde çocuğa dönük yayınların ve çocuğun ele alınışının örneklerini yansıtmaya çalışmıştır. ( Kür;1991)

\section{Yazarlar}

$\mathrm{Bu}$ dergilerde yazıları ve çevirileri yayımlanan çevirmen ve yazarlar arasında daha sonra öncü yazarlar olarak tanımlayabileceğimiz isimler de vardır. Cumhuriyet döneminde bu yazar ve çevirmenler Tevfik Fikret, Ali Ulvi Elöve, Ahmet İhsan Tokgöz v.s.- öncü tanımlamasını hak edecek çalışmalar yapmışlar öncü çevirmen olarak başlayıp öncü yazar olarak edebiyat dizgesinde yerlerini almışlardır. (Krş. Kür,1991)

\section{İlk çeviriler}

Çevrilen kitaplara bakıldığında Batı'nın yaşadığı gelişim sürecinin biraz geç de olsa bizde de yaşandığını görmek mümkündür. Batı'da 1719 yılında yayınlanan, insanın akıl ve tekniği kullanarak doğaya ve dünyaya hükmedebileceğini ve insanın bu konuda yeterli birikime ve akla sahip olduğu inancını vurgulayan Danıel Defoe'nın "Robınson Cruseou" romanı bizde 1864 yllında Ahmet Lütfi çevirisiyle "Hikaye-i Robinson" adıyla yayınlanır.

1726 yllında yayınlanan, çözümsüz savaşım ve hoşgörüsüzlüğün yoğun olarak varlığını, hırsının peşine takılan insanın sonuçta yaşayacağı boşluğu, geriye umutsuzluk ve yalnızlıktan başka birşeyin kalmadığını ortaya koyan Jonathan Swift'in 'Gulliver' romanı da 1872 yılında Mahmud Nedim tarafından çevrilir ve 'Gulliver Nam Müellifin Seyahatnamesi' adıyla yayınlanır.

\section{Anlamı}

Çeviri çocuk edebiyatının bu iki kitapla başlaması Batı'daki aydınlanma sürecinin çeviri yoluyla bize yansıması olarak algılanabilir.

\section{Diğer çeviriler}

Bu dönemde Jules Verne'nin kitapları da yayınlanır. 'Gizli Ada' (1869) 'Seksen Günde Devrialem' (1889) 'iki Sene Mektep Tatili' (1891) Ahmet İhsan Tokgöz çevirileridir. 'Merkezi Arza Seyahat' (1885) 'Beş Hafta Balon ile Seyahat' (1888) Mehmet Emin tarafindan çevrilmiştir. Bu dönemde ayrıca Şinasi, Recaizade Mahmut Ekrem ve Ahmet Mithat Efendi'nin La Fontaine ya da başka şair ve yazarlardan şiir ve düzyazı biçiminde çevirdiği fabl türünde kısa hikayeler ve uyarlamalar vardır. 


\section{Nedenleri}

Avrupa kültürüne ve sanayileşmesine ve aydınlanma sürecine artan ilginin somut belirtileri olan bu eserlerin yayınlanması, toplumda yeni bir kültürün oluşturulması ve bu kültürle yetişmiş kuşakların yaratılması çabasıdır.

\section{Cumhuriyet dönemi}

Bu çabalar, Cumhuriyet Dönemi’nde de aynı yoğunlukta devam eder. Bu dönemin özelliği, Tanzimat Dönemi'nde aydın hareketi olarak başlayan ve devam eden sürecin, devlet politikası olarak ele alınması ve sürdürülmesidir.

\section{Cumhuriyet döneminde temel anlayış}

Cumhuriyet döneminde çocuk edebiyatına egemen olan temel anlayış, ulus devlet ve modern bir toplum yaratmaya dönük olmuştur.Ortaya konan eserlerde dil bilincini geliştirmek önemsenirken, modern insan tipi konusunda özellikle çeviriler önemli bir rol oynamıştır. Bu süreç altmışlara kadar devam eden bir süreçtir.

\section{6o'lara kadar ve 6o'lardan sonra}

6o'lı yıllara kadar Modernleşme-Aydınlanma anlayışı egemenken 6o'lı yıllarda sol anlayış öne çıkar. Özellikle yetmişli yıllarda sol çocuk edebiyatı gelişme gösterir. Bu dönemde ünlü yazarlara çocuk kitapları yazdırılır. Ancak bu gelenek fazla sürmez. Bu dönemden günümüze Rıfat Ilgaz, Aziz Nesin, Fakir Baykurt gibi ünlü yazarların kitapları ulaşabilmiştir.Ayrıca 70'li yıllarda ideolojik bir aidiyet içinde olmayan Kemalettin Tuğcu'nun kitapları çok satan kitaplar olmuştur.

\section{8o sonrası}

Son on yıllarda yaşanan sosyo-ekonomik gelişmeler çocuk edebiyatının ve ilişkili çocuk medyasının şaşırtıcı şekilde değişmesine ve gelişmesine yol açmıştır. Bu süreçte hem çocuk yaklaşımı, hem de çocuk edebiyatı ve yayıncılığı hızlı bir değişim göstermiş ve çocuğa dönük her türlü üretim başlıca bir alan oluşturmuştur.

\section{9o'lar sonrası}

80 lerde başlayan ve 90 lı yllarda gelişerek devam eden "tüketim toplumu"na geçiş süreci aynı zamanda çocuğa bakışı da değiştirmiş ve onu da tüketimin ana hedef kitlesi haline getirmiştir. Bu ise çocuğa bakışı değiştirmiş ve onu merkez konumuna taşımıştır. O dönemde başlayıp günümüze uzanan bir süreçte çocuğa bakıştaki değişimle birlikte ona dönük edebiyatın ana ekseni değişmeye başlamıştır. Biçim, biçem ve içerik değişimlerinin yanısıra aynı zamanda kitapların formatları, baskı kaliteleri de değişime uğramıştır. Ama tüm bunlar edebiyatın gelişimini ancak biçimsel olarak sağlamış ve yine de bu alanda çeviri hakim rolünü sürdürmüştür. 


\section{Türkiye'de klasik yayıncılığı}

Klasikler 130 yıldır yayınlanan kitaplardır. 60 sonrasında her on yldda bir yeniden gündeme gelmiş ucuz maliyeti ve saygın konumu nedeniyle yeniden ve yeniden basılmıştır. Türkiye'de klasikleri yayın yelpazesinde bulunduran 100'den fazla yayınevi vardır. Ticari olarak elverişli bir yayın alanıdır.

Bu ürünler farklı anlayışlar doğrultusunda çevrilmiş, uyarlanmış, indirgenmiş ve yeniden yazılmıştır.

\section{0-2010 arasında en çok çevrilen metinler}

Andersen (Masallar); Frances Burnet (Küşük Prenses); Carlo Collodı (Pınokyo); Danıel Defoe (Robınson Cruseau); Charles Dickens; Jonathan Swift (Gulıver); Mark Twain (Tom Sawyer); Jules Verne; La Fontaine; Samet Behrengı; Enİd Blyton;Cervantes(DonKışot); Alexandre Dumas (Monte Cristo Kontu);Rene Goscinny (Pitırcıkdızısı); Eleanor Porter (pollyanna); Frances Burnet; Lewıs Carrol; Grımm Kardeşler, Vlktor Hugo; Sempe ve Goscınny; Johanna Spyri; R. Luise Stevenson; Florens Stratton; Jonathan Swıft; Rudyard Kiplıng Hector Malot; Ferenc Molnar; R. A. Montgomery; EdwardPackard; CharlesPerrault .

Yukarda belli bir seçki olarak değinilen yazar ve kitapların Tanzimat döneminden bu yana yüzlerce baskı yaptığını ve her on yılda yeniden popülerleştiğini söylemek mümkündür.

\section{Çocuk edebiyatı klasik çevirilerinin çoğul-dizge kuramı açısından değerlendirilmesi}

Tanzimat döneminde başlayan çeviri sürecinin özellikle modernleşmeye dönük olması ve dönemsel baktığımızda henüz bir çocuk edebiyatı dizgesinin olmaması bu alanın çeviri yoluyla doldurulması zorunluluğunu doğurmuştur ve 1859 yllında Telemak çevirisiyle başlayan süreç günümüze kadar kendini devam ettirmiştir. Buna dönük bir sorgulama yaptı̆̆ımızda Even Zohar’n çoğul dizge kuramı çıkar karşımıza.

Tanzimat döneminde yaratılmaya başlanan çocuk edebiyatı Zohar’ın Çoğul Dizge kuramıyla oldukça fazla örtüşük yanlar içerir. "Genç bir edebiyat kısa zamanda bütün yazın tür ve tiplerinde önemli metinler üretemediğinden, başka edebiyatların deneyiminden yararlantr ve böylece çeviri yazın bu edebiyatın önemli dizgelerinden biri durumuna gelir. Even-Zohar'ın bu varsayımı Tanzimat dönemindeki çeviri etkinliğinin durumunu açıklığa kavuşturmaktadır. Henüz Çocuk edebiyatını oluşturamamış, üstelik yeni bir kültürün uygulanma çabaları içinde olan Tanzimat, bu boşluğu doldurmak için çeviriye yönelmiş ve kültürü uygulama olanağı yaratabileceği eserleri çevirerek amaçlarına dönük bir çocuk edebiyatını yaratma çabalarına girmiştir.(karş Zohar 1978:14-20)

\section{Skopos kuramı}

Erek odaklılık açısından baktığımızda ise bu kuramın alana dönük önemli yanını vurgulayan özelliği ise şöyledir:

Skopos kuramında çevirmenin rolüne büyük önem verilir. kurama göre çevirmen, sorumluluklarının bilincinde olan, karar verme ve bunları uygulama yetisine sahip profesyonel bir kişi olarak niteler. Çevirmen, ne yaptığını bilen ve kararlarını açıkça dile getirebilen bir uzman kişidir ve bu nedenle çevirmen aldığı kararları ve bunların nedenlerini belirten bir önsöz yazarak gerektiği zaman kendini savunabilmelidir. (Vermeer 1989;35) 
Özellikle Tanzimat döneminde, çevirmenin baskın konumda olduğunu ve öncü rolü oynadığını göz önüne alırsak bu durum net biçimde ortaya çımaktadır. Çevirmen ne yaptığını bilmektedir ve toplumun değişimine önemli katkılar yaptığını düşünmektedir.

\section{Çevirmen tavrı}

Klasikleri ilk çeviren çevirmenler daha çok metne sadakat üzerinde durmuş ve metinle birlikte yazarına ve temsil ettiği "moderniteye" saygılı davranmıştır.

İlk Jules Verne çevirmenlerinden Servet-i Fünun'cu Ahmet İhsan Tokgöz Jules Verne için şunları söyler:

Jules Verne’in ölümü Üzerine

Jules Verne'in vefatını telgraflar bu hafta haber verdi. Bu müellif-i bimisalin, bu alim-i gayurun namını bütün cihan-ı maarif ve mütalaa tanır, takdir ve tebcil eder ise de asar-ı istifade - bahşının mütercimi olmak sıfatıyla Jules Verne'in vefatı bize daha ziyade tesir eyledi. Verne şimdiye kadar on beș kadarı büyük mütebakisi ufak seksen beş roman yazmış, neşretmiştir. Bunlardan en ziyade Avrupa'da mazhar-1 rağbet olup her lisana tercüme olunanları bu mauharrir-i aciz Türkçe'ye tercüme ve kariin-i Osmaniyeden gördüğü rağbet-i fevkalade sayesinde tab’a muvaffak oldu ki onların esamisi de intişarları sırasıyla şunlardır(Ercilasun, 1996,73)

\section{Uyarlamaya dönük yaklaşımlar}

Pinocchio, Heidi veya Robinson'un ve benzeri klasiklerin dilsel ve kültürel sinırlarının ötesindeki aktarımlarını ele aldığımızda, klasikleşmiş çocuk edebiyatı eserlerinin ne denli dönüşüm yetenekleri olduğunu görürüz. Hedef kültüre yapılan çeviri ve uyarlamalar, uyarlama bağlamında zamansal ve kültürel soruların gerekliliğini ortaya koyar. Çocuk edebiyatı klasiklerinin genel edebiyattan ayrılan farkı da özellikle kendisini bu değişik uyarlama çeşidinde kendisini göstermektedir. Tarihsel algılama yeteneği bulunmayan genç bir okur kitlesine, eski metinleri algılanabilir hale getirme gerekliliği düşüncesiyle bu eğilim ortaya çıkar. Ama bu eğilim, kültürel uyarlama ve kültürel anlama düşüncesinin dışında ideolojik eğilimlere hizmet etmeye başlarsa bu durumda metin içerik olarak temel paradigmasını yitirir ve anlam kaymaları gerçekleşir. O zaman metin kendi kimliğini yitirmiş olur.

Bu anlaşılabilir kılma gerekçesiyle ortaya çıkan değişiklik yapma ve müdahale etme hakkı başıboşluk tehlikesini taşımaktadır. Çevirmen ve editör, metinleri uygun hale gelene kadar değiştirebileceklerini ifade etmektedirler. Bu sinırsızlık anlamına gelir.

Tamamen piyasa ihtiyaçlarına göre hazırlanmış çevirilerde ise, bunun da ötesinde, metni sadece anlaşılabilir hale getirme değil de ayrıca "eğlenceli" hale getirmek veya ideolojik uyarlamada meşru sayılmaktadır. Yani genel kural olarak netin dokunulmazlığının en önemli kural olduğu genel edebiyat alanıyla karşılaştırdığımızda, çocuk edebiyatı klasiklerinin uyarlamaları birbirlerine uymamaktadır.

\section{Tokgöz’ün Jules Verne çevirilerinden örnekler}

1868 yllında doğan Ahmet İhsan Tokgöz, temel eğitimini İşkodra ve Şam'da tamamlamasının ardından 1887 'de Mekteb-i Mülkiye'yi bitirdi. Okul yıllarında başlayan edebiyat tutkusu Fransızcadan, özellikle de Jules Verne'den yaptığı çevirilerle üst düzeye taşındı. Çevirileri arasında, Seksen Günde Devr-i Alem (gayr-i musavver ikinci tab); Gizli Ada (Gayrı musavver); Deniz Altında Seyahat(Musavver); Kaptan Grant'ın Çocukları (Musavver); Kaptan Hatteras'ın Sergüzeşti (Mus.); 
Cevv-i Havada Seyahat (Mus.); İki Sene Mektep tatili (Mus.); Mihver-i Arz (Mus.); Yer Altında Seyahat (mus.); Araba İle Devr-i Alem (Mus.) saymak mümkündür.(Ercilasun, 1996,73)

\section{Günümüzde çocuk edebiyatı klasiklerine çevirmen ve yayıncı yaklaşımı}

Günümüzde çocuk edebiyatı klasiklerinin yayımında kültür taşıyıcılığından daha çok ticari bir anlayış öne çıkmaktadır. Bunların "en tanınan" ve genel anlayış olarak "en sakıncasız" kitaplar olarak bilinmesi, ayrıca MEB tarafından 100 Temel Eser listesinde yer verilmesi onlara dönük ilgiyi artırmıştır. Bu ilgi o dönemde salt ticari bir kaygı olmaktan çıkıp ideolojik bir anlayışa da dönüşmüştür. Bazı yayınevleri kendi düşünsel anlayışları doğrultusunda metinlere müdahale etmeye başlamış ve yapılan müdahale metnin temel anlamını, hatta temel anlayışını (metnin paradigması)bozan bir düzeye ulaşmıştır.

Klasik çevirileri son 25 ylda birçok yayınevince üzerinde çevirmeni bulunmayan metinler halinde yayınlanmaya başlamıştır. $\mathrm{Bu}$, alanın denetimsiz olması nedeniyle gerçekleşmiş, aynı zamanda klasik çevirilerinin sahipsizliği nedeniyle(70 yl kuralı)² çoğunlukla çevir meni bile olmadan kitaplara (özellikle çocuk edebiyatında çok yapılıyor) yayınlanmıştır. Bu kitapların iç sayfasında yayına hazırlayan diye bir ibareyle metni kimin hazırladığı belirtilmesine karşın, çoğu zaman bu kişinin çevirmen olması gibi bir durum söz konusu olmamıştır. Çevirmeni belirtilmeyen bu metinler, aslında piyasada önceden çevrilmiş metinlerden yola çıkarak farklı amaçlar doğrultusunda hazırlanmış metinler olarak geçerlidir. Bunlar ya ideolojik bir uyarlama amaciyla, ya da dinsel bir müdahaleyle, veya ticari amaç doğrultusunda kısaltılarak hazırlanmışlardır. 96 sayfanın altında kalan kitapların bandrol zorunluluğundan muaf tutulması metinlerin kısaltılması için ahlaki olmayan bir fırsat oluşturmuştur. Bugün piyasada (örneğin 48 sayfadan başlayarak 1800 sayfaya kadar ulaşan)10o den fazla Victor Hugo 'nun "Sefiller" romanını bulmak mümkündür 3

Klasikler topluma emanet edilmiş ve onun değerbilirliğine bırakılmıştır.Bu yapılmadığında başka bir deyişle sahipsizleşmiş metinlerdir diyebiliriz.. Bu nedenle denetlenmesi olanaksızdır. Günümüzde klasik yayınlayan yayınevi sayısını saptamak mümkün değildir. Kaçak kitap basan (korsan) yayınevlerini hesaba katarsanız sayının oldukça yüksek çıkması mümkündür. 100 den fazla yayınevinin kataloğunda klasikler mevcuttur. Genel olarak 2500-3000 civarında kitabın klasik yayın olduğunu söyleyebiliriz.

Piyasa araştırması yaptığınızda 96 sayfalık Robinson Crusoe'ya rastlayabilirsiniz. Aynı zamanda üzerinde çevirmeni yazan 240 sayfalık olanını da.. Aralarındaki fiyat farkını ele alırsanız hangisinin okunacağını söyleyebilirsiniz. Ayrıca fiyat konusunda aynı kitabın 0.5 YTL olanından tutun da 16YTL olanına kadar geniş bir yelpazesi söz konusudur. (Krş. Neydim, 2006)

\section{Sonuç}

Tanzimat döneminde başlayan ve Cumhuriyet dönemiyle devam eden süreçte "Klasikler" yazın alanında modernleşmenin önemli aracı olarak kabul görmüşlerdir. Bu saygı süreç içinde onların denetimsizliğine neden olmuş ve müdahaleye açık bir alan olarak ortaya çıkmıştır. Başlangıçta

\footnotetext{
$2 \quad$ Yazarın ölümünün ardından yetmiş yıl geçtiğinde kitap artık telif dışı sayılıyor ve isteyen hiçbir telif bedeli ödemeden yayınlama hakkına sahip oluyor.

3 Bu konuda var olan internet kitap dağıtım şirketlerinin sayfalarına bakmak yeterlidir
} 
yukarda değindiğimiz gibi klasiklere ve yazarlarına dolayısıyla metne saygı modernleşme çerçevesinde üst düzeyde var olurken son dönemde metne saygıdan daha çok ticari ve ideolojik kaygı öne çıkmıştır.

Tüm bu görünümü erek odaklı kuramlar açısından sorguladığımızda dönemsel bir değişimin ya da değişim çabasının varlığının ve bunun çeviri yoluyla yapıldığının tanıklığını yaptığımızı görebiliriz. Bu tanıklık aynı zamanda aynı metinlerin iki farklı kültür anlayışı tarafından nasıl kullanıldığının da tanıklığı olmaktadır.

\section{Kaynakça}

Alpaslan, G. G. (2007). Tercüme-i Telemak. (Y. K. Paşa, Çev.) Ankara: Öncü.

Collodi, C. (1994). Pinokyo. (G. Suveren, Çev.) İstanbul: Altın Kitaplar.

Ercilasun, B. (1996). Ahmet İhsan Tokgöz. Ankara: Kültür Bakanlığı Türk Büyükleri Dizisi.

Even-Zohar, I. (1987, Ocak). Yazınsal "Polisistem" içinde Çeviri Yazının Durumu. (S. P. Adam, Dü., \& S. Paker, Çev.) Sanat(14), 59-67.

Kurultay, T., \& Neydim, N. (1998). Çocuk ve Gençlik Edebiyatımızın Oluşumunda çevirilerin yeri ve Çeviri Çocuk Edebiyatının Durumu Üzerine (Cilt 1). İstanbul: Binbir Kitap.

Neydim, N. (2006). Masumiyetini Tamamen Kaybeden Seçki. Radikal.

Özkırımlı, A. (1990). Türk Edebiyatı Ansiklopedisi. İstanbul: Cem.

Porter, H. E. (1984). Pollyanna. (T. Andaç, Çev.) İstanbul: Örgün.

Tellioğlu, B. (1998). Hans Vermeer'in Skopos Kuramında Görecelilik Kavramının Yeri ve Bu Kavramın Çeviri Eleştirisine Yansımaları, Görece-Görecelilik. Çeviribilim Uygulamaları, 159-166. 